\title{
Using an Absolute Cavity Pyrgeometer to Validate the Calibration of a Secondary Standard Pyrgeometer Outdoors, Independent from the Reference Value of the Atmospheric Longwave Irradiance
}

\author{
Ibrahim Reda, Afshin Andreas, Peter Gotseff, Mark Kutchenreiter \\ National Renewable Energy Laboratory (NREL), Golden, Colorado, USA \\ Email: ibrahim.reda@nrel.gov
}

How to cite this paper: Reda, I., Andreas, A., Gotseff, P. and Kutchenreiter, M. (2020) Using an Absolute Cavity Pyrgeometer to Validate the Calibration of a Secondary Standard Pyrgeometer Outdoors, Independent from the Reference Value of the Atmospheric Longwave Irradiance. Atmospheric and Climate Sciences, 10, 530-537. https://doi.org/10.4236/acs.2020.104027

Received: September 11, 2020

Accepted: September 26, 2020

Published: September 29, 2020

Copyright $\odot 2020$ by author(s) and Scientific Research Publishing Inc. This work is licensed under the Creative Commons Attribution International License (CC BY 4.0).

http://creativecommons.org/licenses/by/4.0/ (c) (i) Open Access

\begin{abstract}
Accurate measurements of broadband outdoor longwave irradiance are important for renewable energy applications and the study of the atmosphere and climate change. A unique method of pyrgeometer calibration has been developed to improve the measurement uncertainty [1]. The results of this method yielded irradiance values within $\pm 3 \mathrm{~W} / \mathrm{m}^{2}$ of those traceable to the World InfraRed Standard Group (WISG). This article describes a technique for validating this pyrgeometer calibration method using two Absolute Cavity Pyrgeometers (ACPs). The ACPs and pyrgeometer model PIR were deployed outdoors and the irradiance measured by the PIR was compared against the average irradiance measured by the two ACPs. The irradiance measured by the PIR was calculated using two equations, NREL equation and the Physikalisch Meteorologisches Observatorium Davos (PMOD) equation. The uncertainty with $95 \%$ confidence level $\left(U_{95}\right)$ of the irradiance measured by the PIR using NREL equation equaled $\pm 3.51 \mathrm{~W} / \mathrm{m}^{2}$ with respect to SI and using PMOD equation $U_{95}$ equaled $\pm 2.99 \mathrm{~W} / \mathrm{m}^{2}$ with respect to SI. These results suggest that the PIR calibration method might be useful in addressing the international need for a secondary standard pyrgeometer traceable to SI.
\end{abstract}

\section{Keywords}

Absolute Cavity Pyrgeometer, ACP, Pyrgeometer, WISG, Atmospheric Longwave Irradiance 


\section{Introduction}

The pyrgeometer model PIR was installed outdoors on an aluminum plate that was connected to a temperature controller, see Photo 1 . Adjusting the temperature controller to decrease the pyrgeometer's body temperature changed the pyrgeometer's thermopile output. If the incoming radiation was stable, then the slope of the change in the pyrgeometer's output irradiance $\left(W_{\text {out }}\right)$ versus the change in the thermopile output voltage $(V)$ would equal the pyrgeometer outdoors responsivity (RS), independent from the absolute value of the atmospheric longwave irradiance [1]. We then evaluated the results of the method using two Absolute Cavity Pyrgeometers (ACPs), ACP95F3 and ACP10F3. The ACPs were installed on temperature controllers and operated as described in [2]. The described method addressed the inherent problems related to the spectral difference between the blackbodies and the atmospheric irradiance by calculating RS from the clear sky outdoor calibration and using the actual atmospheric irradiance as the calibration source.

Section 2 describes the procedure, equations, and the mathematical representation of the rate of change of $V$ versus $W_{\text {out }}$.

Section 3 shows the procedure results and the outdoor evaluation of this procedure. The evaluation compared the measured irradiance by the PIR against the average irradiance measured by ACP95F3 and ACP10F3.

Section 4 is the conclusion.

\section{Procedure}

The ACPs and PIR were deployed outdoors from July 20 to August 19, 2020. Two equations were used to calculate the atmospheric longwave irradiance measured by the PIR, as described below in NREL and PMOD equations.

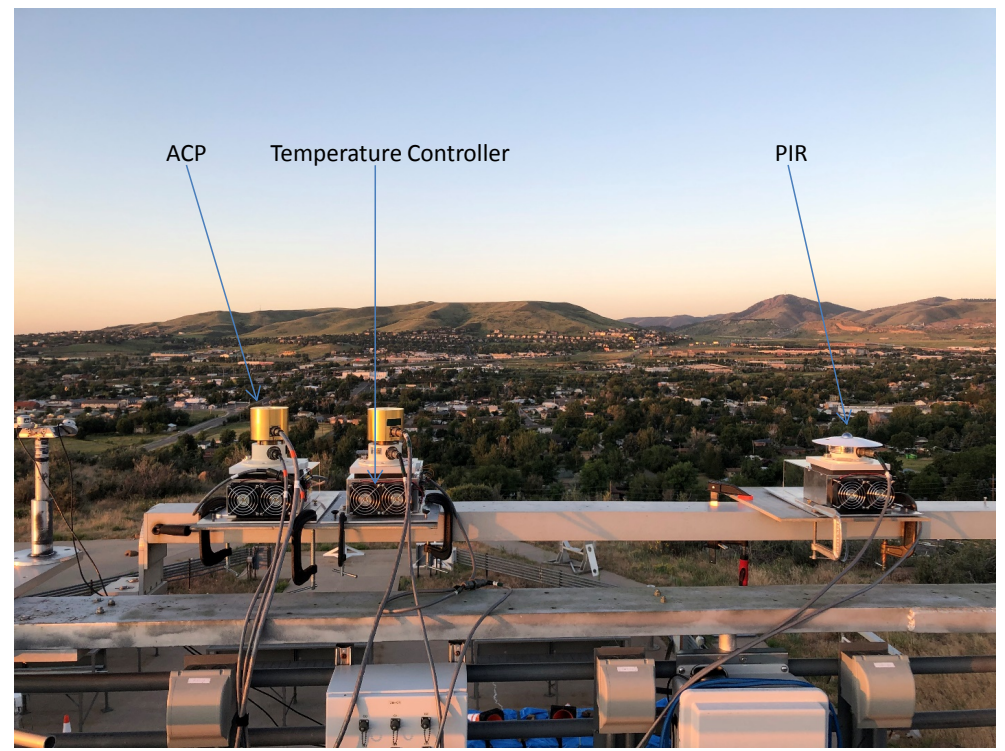

Photo 1. Outdoor set up from left to right of ACP95F3, ACP10F3, and PIR on top of temperature controllers. 
NREL Equation [3]

$$
W_{\text {atm }}=K_{0}+K_{1} V+K_{2} W_{r}+K_{3}\left(W_{d}-W_{r}\right)
$$

where:

$W_{\text {atm }}$ is the atmospheric longwave radiation in $\mathrm{W} / \mathrm{m}^{2}$.

$K_{0}, K_{2}$, and $K_{3}$ are the calibration coefficients of the pyrgeometer, calibrated at the PMOD [4].

$K_{1}$ is the reciprocal of the PIR's RS, calculated from the outdoor calibration described below.

$V$ is the pyrgeometer thermopile output, in microvolts.

$W_{r}$ is the pyrgeometer receiver radiation $=\sigma * T_{r}^{4}$, and $T_{r}=T_{c}+K_{4} * V$, where:

$\sigma$ Stefan-Boltzman constant $=5.6704 \times 10^{-8} \mathrm{~W} / \mathrm{m}^{2} / \mathrm{K}^{4}$.

$T_{c}$ pyrgeometer case temperature, in Kelvin.

$S$ Seebeck coefficient $=39 \mathrm{~V} / \mathrm{K}$.

$n$ number of thermopile junctions $=56$ junctions.

$E$ thermopile efficiency factor $=0.65$ (manufacturer specification).

$K_{4}$ thermopile efficiency factor equal to $1 /(S * n * E)=0.0007044 \mathrm{~K} \cdot \mathrm{uV}^{-1}$.

$W_{d}$ is the pyrgeometer dome radiation $=\sigma * T_{d}^{4}$, where $T_{d}$ is the dome temperature in Kelvin.

Equation (1) is rewritten in the following form:

$$
W_{\text {out }}=W_{\text {atm }}-W_{\text {net }}=W_{\text {atm }}-K_{1} V
$$

where:

$W_{\text {net }}$ is the net irradiance measured by the pyrgeometer thermopile.

$W_{\text {out }}$ is the outgoing irradiance from the pyrgeometer.

$$
W_{\text {out }}=K_{0}+K_{2} W_{r}+K_{3}\left(W_{d}-W_{r}\right)
$$

A fundamental principle for this calibration procedure is to lower the outgoing irradiance while the atmospheric longwave irradiance $\left(W_{\text {atm }}\right)$ is constant, i.e., stable during clear sky conditions to within $1 \mathrm{~W} / \mathrm{m}^{2}$ from the start to end of the calibration, at least 7 minutes. Lowering $W_{\text {out }}$ was achieved by cooling the pyrgeometer's case using the temperature controller. While lowering $W_{\text {oup }}$ all signals from the pyrgeometer were measured every 10 seconds (i.e., thermopile output voltage, $T_{d}$ and $T_{r}$ ). Differentiating Equation (2) with respect to time then yields:

$$
\mathrm{d} W_{\text {out }} / \mathrm{d} t=\mathrm{d} W_{\text {atm }} / \mathrm{d} t-K_{1} \mathrm{~d} V / \mathrm{d} t
$$

If $W_{a t m}$ is assumed constant, Equation 4 then yields:

$$
K_{1}=-\mathrm{d} W_{\text {out }} / \mathrm{d} t
$$

Equation (5) implies that the change of $W_{\text {out }}$ versus the change of $V$ yields $K_{1}$, which is independent from the absolute value of $W_{\text {atm }}$.

Once $K_{1}$ was calculated using the above procedure, Equation (1) was used to calculate the measured atmospheric longwave irradiance for 2 hours, and then the procedure was repeated from a solar zenith angle of $>95^{\circ}(\mathrm{PM})$ to $<95^{\circ}$ 
(AM).

$$
\begin{aligned}
& \text { PMOD Equation [4] } \\
& \qquad W_{a t m}=V / C\left(1+K_{1} \sigma T_{b}^{3}\right)+K_{2} W_{b}+K_{3}\left(W_{d}-W_{b}\right)
\end{aligned}
$$

where $C$ is the pyrgeometer responsivity and $T_{b}$ is the case temperature.

As in the NREL method described above, where $W_{\text {atm }}$ is assumed to be constant, differentiating Equation 6 with respect to time yields:

$$
\mathrm{d}\left(V\left(1+K_{1} \sigma T_{b}^{3}\right)\right) / \mathrm{d} t / C=-K_{2} \mathrm{~d} W_{b} / \mathrm{d} t-K_{3} \mathrm{~d}\left(W_{d}-W_{b}\right) / \mathrm{d} t
$$

For simplicity, Equation (7) is rewritten as:

$$
C=\mathrm{d} F / \mathrm{d} W_{\text {out }}
$$

where $F=V\left(1+K_{1} \sigma T_{b}^{3}\right)$ and $W_{\text {out }}=-K_{2} W_{b}-K_{3}\left(W_{d}-W_{b}\right)$.

Equation (8) implies that the change of $F$ versus the change of $W_{\text {out }}$ yields $C$, which is independent from the absolute value of $W_{\text {atm }}$.

The ACP's Measurement Equation [2]

To measure the atmospheric longwave irradiance:

$$
W_{a t m}=\left(K_{1} V+(2-\varepsilon) K_{2} W_{r}-(1+\varepsilon) W_{c}\right) / \tau
$$

where:

$W_{\text {atm }}$ is the atmospheric longwave irradiance $\left(\mathrm{W} / \mathrm{m}^{2}\right)$.

$K_{1}$ is the reciprocal of the ACP's responsivity $\left(\mathrm{W} / \mathrm{m}^{2} / \mathrm{uV}\right)$.

$V$ is the thermopile output voltage $(\mathrm{uV})$.

$\mathcal{E}$ is the gold emittance.

$K_{2}$ is the emittance of the black receiver surface.

$W_{r}$ is the receiver irradiance $\left(\mathrm{W} / \mathrm{m}^{2}\right)$.

$W_{c}$ is the concentrator irradiance $\left(\mathrm{W} / \mathrm{m}^{2}\right)$.

$\tau$ is the ACP's throughput.

\section{Results}

The measurement uncertainty was calculated using the following equation:

$$
U_{95}=\operatorname{SQRT}\left(U_{95 \mathrm{ACP}}^{2}+U_{95 \mathrm{PIR}}^{2}\right)
$$

where $U_{95 \mathrm{ACP}}$ equals $\pm 2 \mathrm{~W} / \mathrm{m}^{2}$ with respect to SI [2], using the NREL equation $U_{95 \mathrm{PIR}}$ equals $\pm 2.88 \mathrm{~W} / \mathrm{m}^{2}$ with respect to ACP; therefore, $U_{95 \mathrm{PIR}}$ equals \pm 3.51 $\mathrm{W} / \mathrm{m}^{2}$ with respect to SI. Using the PMOD equation, $U_{95 \mathrm{PIR}}$ equals $\pm 2.22 \mathrm{~W} / \mathrm{m}^{2}$ with respect to ACP; therefore, $U_{95 \mathrm{PIR}}$ equals $\pm 2.99 \mathrm{~W} / \mathrm{m}^{2}$ with respect to SI.

Photo 1 shows the outdoor set up of ACP95F3, ACP10F3, and PIR. Table 1 is a sample list of the calculated $K_{1}$ for the PIR (NREL), ACP95F3, ACP10F3, and C for PIR (PMOD). Figure 1 and Figure 2 show $W_{\text {net }}$ versus $\mathrm{V}$ for ACP95F3 and ACP10F3. Figure 3 shows $W_{\text {out }}$ versus $V$ for the PIR using the NREL equation. Figure 4 shows $W_{\text {out }}$ versus $F$ for the PIR using the PMOD equation. Figure 5 shows the average irradiance of the ACPs and the PIR using NREL and PMOD equations. Figure 6 shows the difference between the ACPs average irradiance and the PIR irradiance using NREL and PMOD Equations. Figure 7 shows the atmospheric water vapor content. 


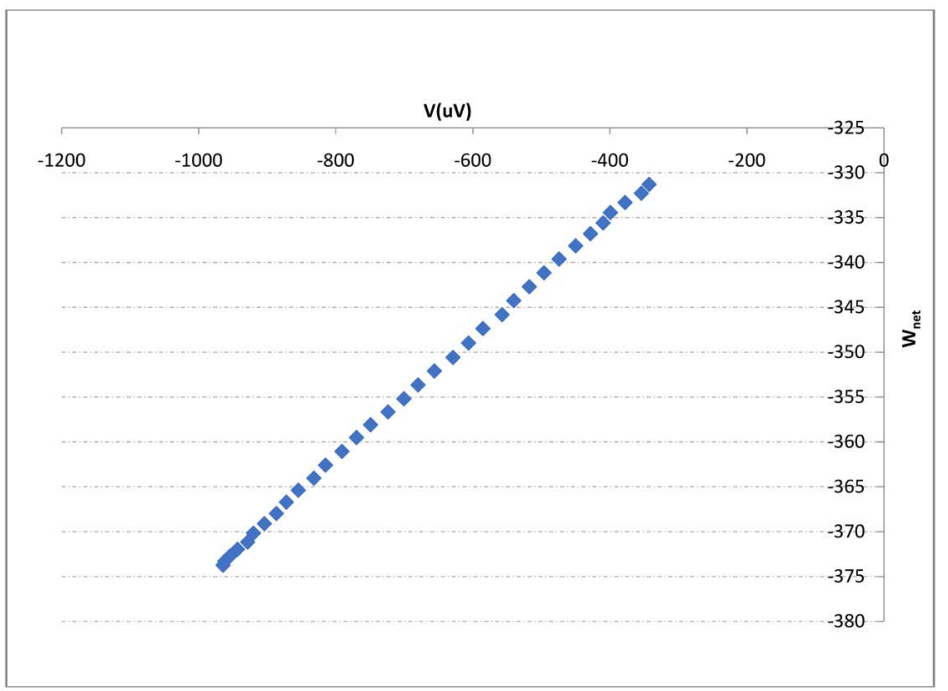

Figure 1. $W_{\text {net }}$ versus thermopile output voltage during the calibration of ACP95F3.

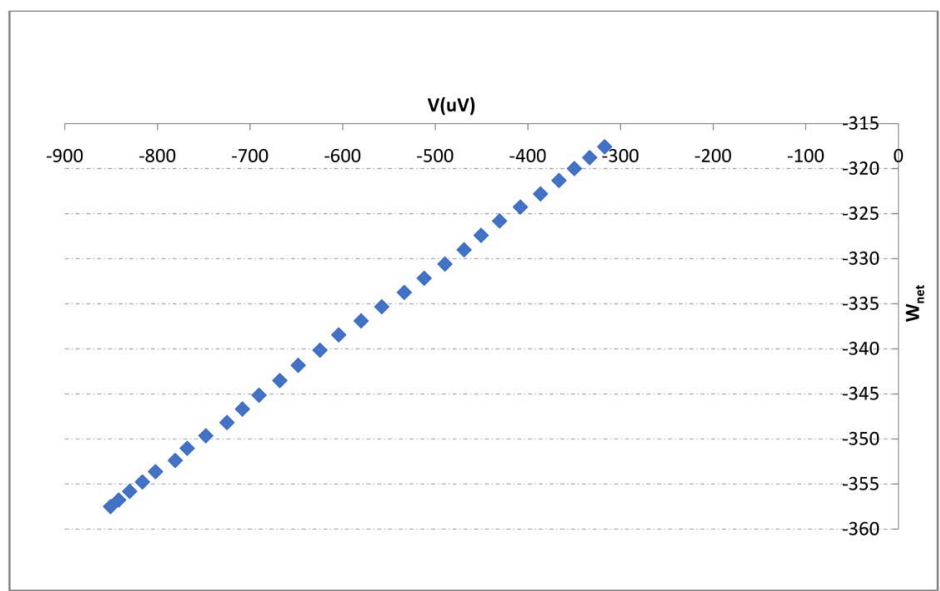

Figure 2. $W_{\text {net }}$ versus thermopile output voltage during the calibration of ACP10F3.

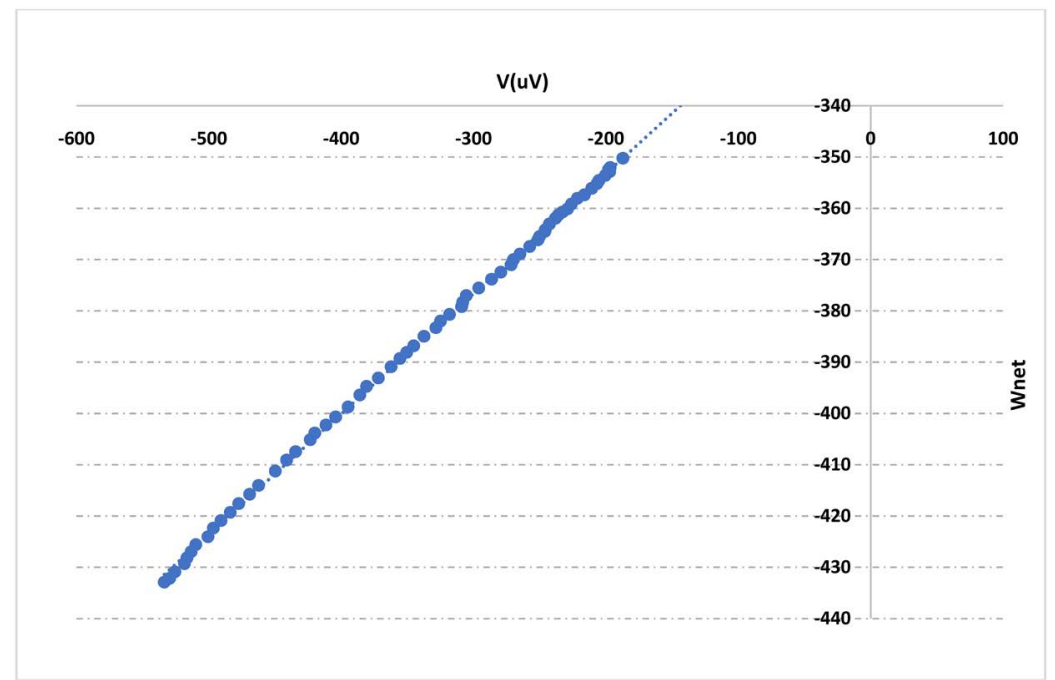

Figure 3. $W_{\text {out }}$ versus thermopile output voltage during the calibration of PIR31197F3 using NREL equation. 


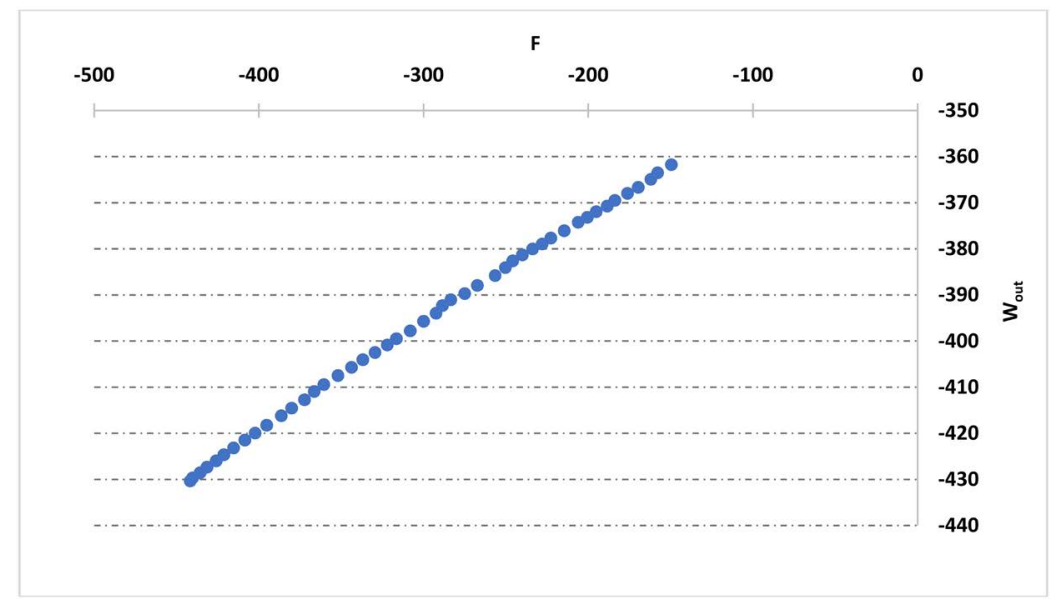

Figure 4. $W_{\text {out }}$ versus F during the calibration of PIR31197F3 using PMOD equation.
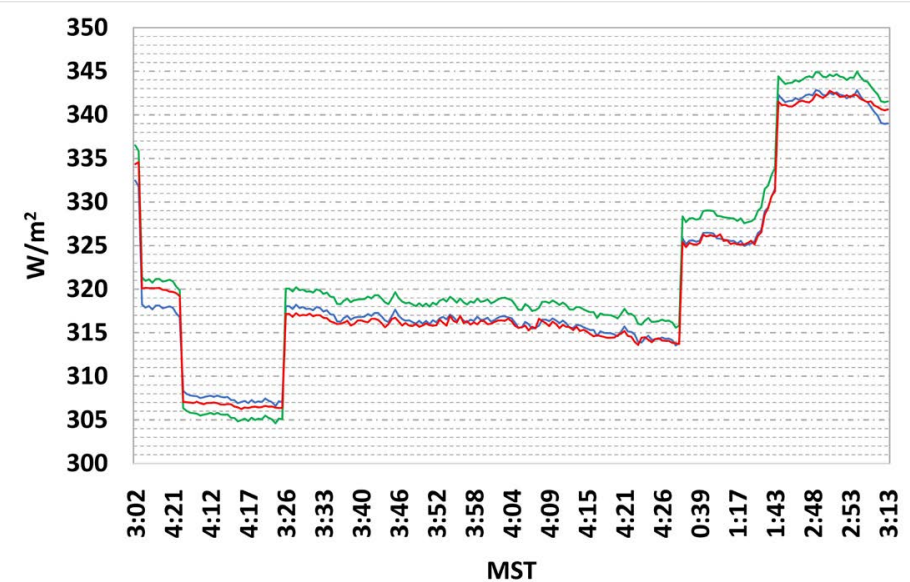

- Win NREL - Win PMOD - ACP(AV)

Figure 5. ACPs average irradiance and PIR31197F3 irradiance versus MST.

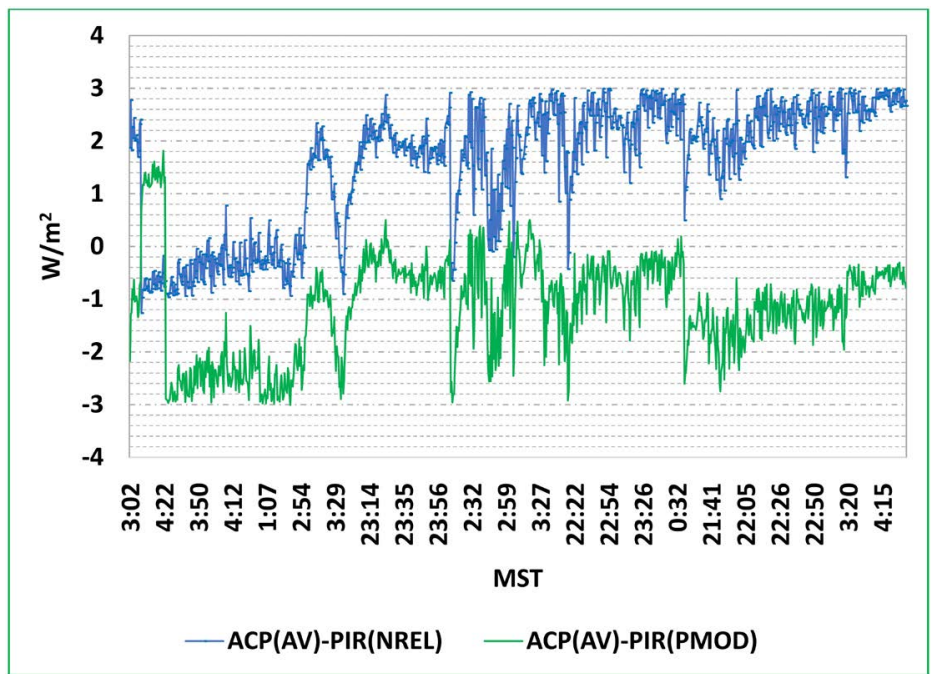

Figure 6. Difference between ACP's average irradiance and PIR31197F3 irradiance versus MST. 


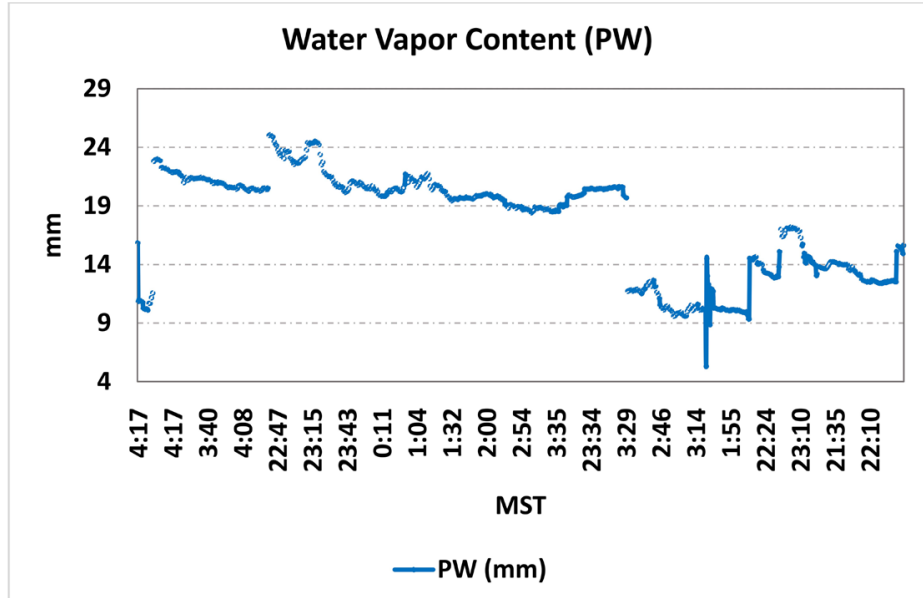

Figure 7. Water vapor content during data collection versus MST.

Table 1. Sample of the calculated $K_{1}$ for PIR (NREL), ACP95F3, ACP10F3, and C for PIR (PMOD).

\begin{tabular}{ccccc}
\hline \multirow{2}{*}{ Date } & \multicolumn{3}{c}{$\mathrm{K}_{1}$} & $\mathrm{C}$ \\
\cline { 2 - 5 } & PIR (NREL) & AC95F3 & ACP10F3 & PIR (PMOD) \\
\hline $\mathbf{7 / 2 0 / 2 0 2 0}$ & 0.2352 & 0.0697 & 0.0707 & 4.5283 \\
$\mathbf{7 / 2 1 / 2 0 2 0}$ & 0.2480 & 0.0674 & 0.0751 & 4.3126 \\
$\mathbf{7 / 2 2 / 2 0 2 0}$ & 0.2556 & 0.0655 & 0.0766 & 4.3075 \\
$\mathbf{7 / 2 9 / 2 0 2 0}$ & 0.2297 & 0.0701 & 0.0791 & 4.4923 \\
$\mathbf{7 / 3 0 / 2 0 2 0}$ & 0.2480 & 0.0807 & 0.0767 & 4.2560 \\
$\mathbf{8 / 1 1 / 2 0 2 0}$ & 0.2561 & 0.0717 & 0.0791 & 4.1499 \\
$\mathbf{8 / 1 5 / 2 0 2 0}$ & 0.2412 & 0.0672 & 0.0759 & 4.4200 \\
$\mathbf{8 / 1 6 / 2 0 2 0}$ & 0.2395 & 0.0714 & 0.0757 & 4.4516 \\
$\mathbf{8 / 1 7 / 2 0 2 0}$ & 0.2396 & 0.0684 & 0.0770 & 4.4476 \\
$\mathbf{8 / 1 9 / 2 0 2 0}$ & 0.2488 & 0.0692 & 0.0783 & 4.2890 \\
\hline
\end{tabular}

\section{Conclusion}

We conclude that using this procedure will result in calibration coefficients that are independent from the absolute value of the atmospheric longwave irradiance. Based on the results, it is possible to achieve an uncertainty of \pm 3.51 $\mathrm{W} / \mathrm{m}^{2}$ using the NREL equation and an uncertainty of $\pm 2.99 \mathrm{~W} / \mathrm{m}^{2}$ using the PMOD equation with respect to SI. These results suggest that the PIR calibration method might be useful in addressing the international need for a secondary standard pyrgeometer traceable to SI.

\section{Acknowledgements}

The authors thank the Atmospheric Radiation Program, the NREL Metrology Laboratory, and the NREL Photovoltaic program for providing the funds for this article. The authors also thank Julian Gröbner of PMOD/WRC for calibrating 
the pyrgeometer used in this article and for pre-reviewing the article before submitting it to the Journal. We strongly thank Martina Stoddard for her persistent administrative support.

\section{Conflicts of Interest}

The authors declare no conflicts of interest regarding the publication of this paper.

\section{References}

[1] Reda, I., Hickey, J.R., Grobner, J., Andreas, A. and Stoffel, T. (2006) Calibrating Pyrgeometers Outdoors Independent from the Reference Value of the Atmospheric Longwave Irradiance. Journal of Atmospheric and Solar-Terrestrial Physics, 68, 1416-1424. https://doi.org/10.1016/j.jastp.2006.05.013

[2] Reda, I., Zeng, J., Schulch, J., Hanssen, L., Wilthen, B., Myers, D. and Stoffel, T. (2011) An Absolute Cavity Pyrgeometer to Measure the Absolute Outdoor Longwave Irradiance with Traceability to International System of Units, SI. Journal of Atmospheric and Solar-Terrestrial Physics, 77, 132-143.

https://doi.org/10.1016/j.jastp.2011.12.011

[3] Reda, I., Hickey, J.R., Stoffel, T. and Myers, D. (2002) Pyrgeometer Calibration at the National Renewable Energy Laboratory (NREL). Journal of Atmospheric and Solar-Terrestrial Physics, 64, 1623-1629.

https://doi.org/10.1016/S1364-6826(02)00133-5

[4] Philipona, R., Frohlich, C. and Betz, C. (1995) Characterization of Pyrgeometers and the Accuracy of Atmospheric Longwave. Journal of Applied Optics, 34, 1598-1605. https://doi.org/10.1364/AO.34.001598 